https://doi.org/10.48009/1_iis_2006_102-107

\title{
A NEW TREND IN TEACHING TO MEET AACSB MANDATES: INTEGRATING COMPUTER INFORMATION SYSTEMS AND MANAGEMENT SCIENCE BY USING MICROSOFT.NET AND LINDO API
}

\author{
Andrew A. Tiger, Southeastern Oklahoma State University, atiger@sosu.edu \\ Ming-Shan Su, Southeastern Oklahoma State University, msu@sosu.edu \\ Chandra Fogle, Southeastern Oklahoma State University, cfogle@ sosu.edu
}

\begin{abstract}
In this paper, a change in Information Systems curriculum in alignment with AACSB requirements is proposed that integrates management science math modeling skills with Web-enabled decision support system (DSS) skills; thus delivering a CIS professional that can meet the demands of providing powerful problem solving capability in a relatively easy-to-use format. The literature review found little evidence of this integration; however, the software for teaching this integration is available and affordable. As evidence, an example is provided, demonstrating the need and solution methodology for the integration of math modeling and optimization with Web-enabled DSSs.
\end{abstract}

Keywords: Web-enabled Math Modeling and Optimization, LINDO API, Microsoft.Net, School Location (Consolidation) Problem

\section{INTRODUCTION}

To meet CIS challenges, specifically the development of value-adding decision support systems, a new type of professional is required who combines the skill sets of computer information systems and management science. This new professional will have academic training in cutting edge technology, specifically developing Web-based decision support systems, and a formal background in applying math modeling and optimization to analyze and solve large-scale business problems. Below are four reasons this type of professional is needed.

The first reason is to exploit the Internet's potential as a convenient and efficient way to solve large analytical problems. The World Wide Web has grown rapidly for several reasons: a single user interface paradigm, its distributed architecture, and the growth of open standards. Web browsers make it easy for the novice user to gain access to many diverse sources of information. Often, those who need Web-based problem solving capabilities have little background in either computer information systems or management science. In the past, investment in in-house decision support systems was both expensive and time consuming. Most companies view this type of investment as a distraction from their core business and refuse to pursue it. However, Web-based decision support systems vendors can offer products that are delivered via the web and billed for on an as-needed basis. As a result of this and the Internet's open structure, many people and organizations provide information for delivery and use the Internet for finding information. Moreover, because of its distributed architecture, they constantly provide fresh information, keeping data current. The management science community needs to exploit this potential of the Internet.

The second reason is that the current expertise of exploiting the Internet to provide Web-based math modeling and optimization capabilities is limited to a few companies and individuals that had the foresight to develop Web-based management science tools. When the discipline of operations research and management science emerged, only a few, such as governments, universities, and large companies, had the expertise and the necessary technology to implement. As computing power became more affordable, opportunities were created for more to apply management science. Today, even spreadsheets can be empowered with powerful modeling capability.

The third reason is that the software needed to develop Web-based decision support systems that implement modeling and optimization techniques is readily available, affordable and currently used in many computer information systems and management science programs. However, awareness and integration are needed to complete the educational void.

The final reason is that in 2003, AACSB reintroduced management science as an expected learning experience. Prior, in 1991, AACSB had eliminated this requirement because management science courses were viewed as irrelevant because they were being taught primarily as math courses. However, with the move towards spreadsheet modeling, interest 
in management science has led AACSB to reverse itself [3]. Essentially, the advent of technology created the renewed interest in management science, where the focus is on the decision-making process.

In this paper, we provide the latest research on decision support with Web-enabled optimization followed by an illustration that uses readily available software to solve a simple, but potentially practical facility location problem. Specifically, LINDO API and Microsoft's .NET technologies are used to develop a decision support system for determining the optimal number of high schools in a county (or the school consolidation problem) in the southwest United States.

\section{LITERATURE REVIEW}

As evidence of the need for curriculum development of this integration, our literature search showed that current math modeling and optimization instruction relies on spreadsheets [9, 11]. Little evidence was found that taught integrating math modeling and optimization with Web-enabled DSS. Most of the work thus far has been published by software vendors and their consulting efforts. The SAS Institute [1] used their software to build web-based optimization framework to solve large-scale production-anddistribution problems; inventory replenishment; and supplier portfolio selection. The paper emphasized the power of the SAS software, but did not provide a literature search to demonstrate that other alternatives are available or provide enough detail to design without their assistance. SAS demonstrations are available through their website, http://support.sas.com/sassamples/demos/supplychain /demos/index.html.

Similarly, Livernash and Heuer [7] developed a white paper detailing how to use their Web-based technology in supply chain management, specifically shipment consolidation using genetic algorithms and mixed integer mathematics. As with the SAS Institute, Livernash and Heuer are promoting their products, Flow Logistics and LoadOpt. Lee and Chen [6] demonstrated how the chemical company, BASF, used Web browsers and server-side Java programming to access complex optimization tools to deliver a production planning decision support system. Lee and Chen also emphasize that optimization is particularly well suited to Internet innovations citing that the Optimization Technology Center of Argonne National Laboratory and Northwestern University's Network-Enabled Optimization System (NEOS) project have the mission of providing optimization as an Internet resource. The third party logistics (3PL) company, Owen \& Minor, stated that it is in the process of redesigning its systems from a mainframe orientation to a Web-services environment to optimize ordering, tacking, and restocking of supplies [4]. Luo and Chen [8] used Web technology to provide simulation optimization to solve academic queuing models.

Very recently, a small group of academics have begun to offer curriculum integrating CIS and Management Science. The University of Florida's Department of Industrial Engineering has begun to offer a course in Web-Enabled DSS (http://www.ise.ufl.edu/webdss/) and its faculty has a forthcoming text (http://www.ise.ufl.edu/it/books/ accessubasp/) available in 2006. The text, "Developing Web-Enabled Decision Support Systems," describes how to develop decision support systems involving databases, implement databases using Microsoft Access database management system, and add additional functionalities using Visual Basic (VB) .NET programming language and use ASP.NET technology to ease the process of rendering Web pages. The authors, Ahuja and Pool, also provided a workshop in Developing WebEnabled Decision Support Systems at the 2005 INFORMS Annual Meeting (http://www.informs.org/ Conf/NO2005/web-dss.htm). Heinrichs and McDonald [11] recently chaired a joint session of the Association of Business Information Systems (ABIS) and the Southwest Decision Science Institute (SWDSI) concerning IS enrollment and sustainability.

Two modeling and optimization software vendors, ILOG (http://www.ilog.com/) and LINDO (http://www.lindo.com/) have begun offering products for creating Web-based applications. In the next section, we demonstrate how LINDO's product, LINDO API, can be used with Microsoft's .NET technologies to provide a Web-enabled decision support system for solving a school location problem.

\section{EXAMPLE PROBLEM - A WEB-ENABLED SCHOOL LOCATION DSS}

In this section, we provide the steps for developing a Web-enabled DSS that uses math modeling and optimization to identify the optimal number and locations of high schools in a geographic region based on region population, population density and school capacities. The school location problem is more commonly known as the facility location problem and has been applied in industry, government, and military. For a good review, see [10]. In its current form, the problem is only 
academic in nature; however, in its completed form, it is an ideal candidate for applying math optimization through a Web-enabled DSS. The reasons that this problem is an ideal candidate include the following: 1) The user is not a modeling or programming expert; 2) the user is unlikely to invest in developing the expertise internally due to infrequent usages of the DSS; 3) the DSS can be applied to different problems by only changing input values; 4) consequently, the DSS is applicable to many end-users; 5) data requirements for the DSS are accessible through the Internet; and 6) the problem is relatively easy to understand, therefore requiring little technical support.

School location problems are recurring problems due to population changes and the increased attention of government spending in education resulting in school consolidations or openings. Part of the decision making process is the trade off of fixed costs of maintaining a school and the traveling costs of transporting students to schools. Figure 1 and Table 1 provide a generic algebraic formulation of the school location problem where no costs are used. Instead, the two costs are represented by weighting factors.

\begin{tabular}{|lccc|}
\hline Minimizew & $\sum_{\text {allj }} y_{j}$ & $+w_{2} \sum_{\text {alliallj }} \sum_{i j} d_{i j} x_{i j}$ & \\
\\
$\sum_{\text {allj }} x_{i j}$ & $=$ & $p_{i}$ & $\forall i$ \\
$\sum_{\text {allj }} x_{i j}$ & $\leq$ & $c_{j} y_{j}$ & $\forall i$ \\
$x_{i j}$ & $=$ & 0 & $\forall i, j$ if $d_{i j} \geq D$ \\
& & $x_{i j} \geq 0$ & $\forall i, j$ \\
& & $y_{j}=0,1$ & $\forall j$
\end{tabular}

Figure 1. Algebraic Formulation of the School Location Problem

Figure 2 shows the network of schools prior to optimization and after optimization. Prior, eight schools exist. Although students do not have a lengthy commute, fixed assets such as utilities, administration resources, bus fleets, etc. are heavily underutilized and expensive. Optimization suggests eliminating all but three schools, resulting in improved utilization of resources. The obvious disadvantage is a lengthier commute. Optimization provides the ability to see the tradeoff of commuting costs and fixed costs associated with maintaining a school.
Table 1. Variable Notation and Description for the School Location Problem

\begin{tabular}{cl}
\hline Variable & Description \\
\hline$x_{i j}$ & $\begin{array}{l}\text { Decision variable - The number of } \\
\text { students from population area } i \\
\text { going to school location } j\end{array}$ \\
$y_{j}$ & $\begin{array}{l}\text { Decision variable }-0 / 1 \text { variable if } \\
\text { school location } j \text { is selected }\end{array}$ \\
$w_{1}, w_{2}$ & $\begin{array}{l}\text { Input }- \text { Weight factors (1 is for } \\
\text { number of schools; } 2 \text { is for total } \\
\text { distance traveled) }\end{array}$ \\
& $\begin{array}{l}\text { Input - Distance (miles) from } \\
\text { population area } i \text { to school location } j\end{array}$ \\
$d_{i j}$ & Input - Student population of area $i$ \\
$p_{j}$ & Input - Capacity (students) of school \\
& location $j$
\end{tabular}

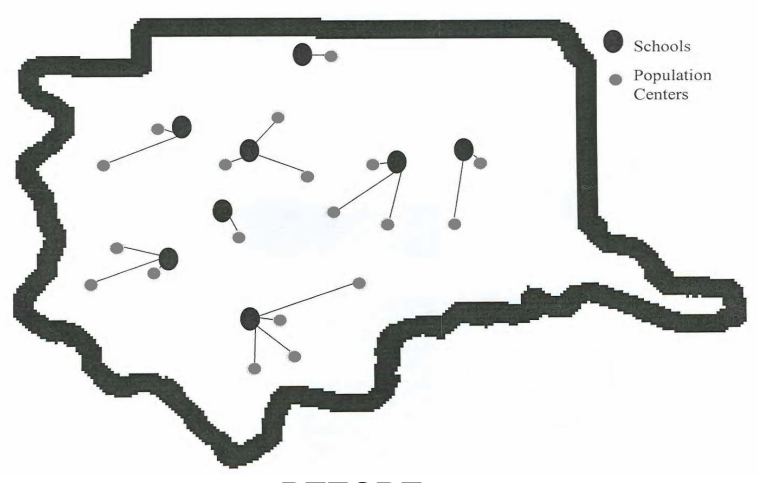

BEFORE

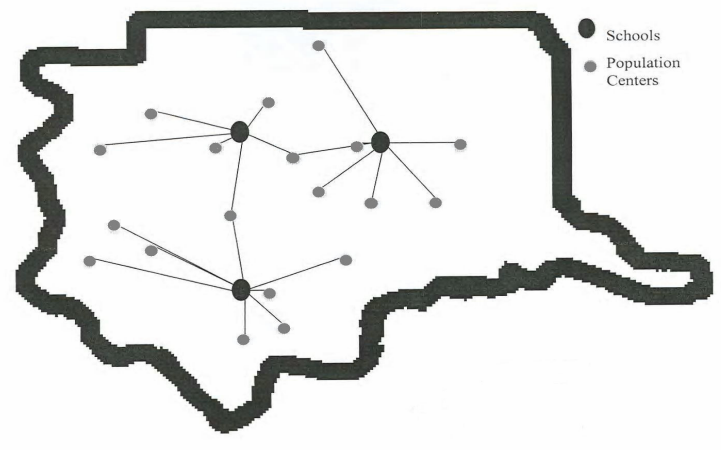

AFTER

Figure 2. School Network Before and After Optimization

Optimization does not replace human decision making. It only provides a baseline that is consistent, fair, and fast. The target users for the Web-enabled 
DSS are legislators who often have to address school openings/closings, yet may not have the expertise or time to maintain the DSS.

\section{THE DSS STRUCTURE}

The School Location DSS is a three-tiered WebEnabled DSS, as shown in Figure 3. Web Controls from ASP.NET and VB.NET are used to build the GUI for the presentation tier. ASP.NET, VB.NET, LINDO API, and ADO.NET are used to build the solution for the business tier, and a MS-Access database is used as the DBMS for the data tier.

In the application, when a user requests the WebForm1.aspx page, the request is forwarded to Microsoft's IIS web server, and then a series of aspx page parsing, data processing, database accessing, LINDO API library interacting and HTML page generating events occur. The user will receive a Web form in a browser, from which a user can modify inputs and/or click the Optimize button to find out the optimal (minimum) number of schools to accommodate all the students from different regions. For access to the code in its entirety, please contact the authors. Figure 4 demonstrates the Web site interface.
Some features of this DSS application consist of the following:

- Providing client-size scripts for the RequiredField and Range Validation web controls as shown if Figure 4 to make sure the student population value once entered will fall in the range between 0 and 50,000 students or no blank value is allowed.

- Providing a Javascript Pop-up dialog to remind a user to click the Update or Cancel hyperlink once in the editing mode before clicking another button (e.g., Compute, Reset) or editing hyperlink in different row.

- Utilizing the DataGrid_Itembound() function to use a different color to represent the school that has been selected.

- Customizing the ColumnTemplate session to incorporate a student population dropdownlist for user selection and a textbox for user editing.

- Caching the Dataset and various values to improve the performance of web accessing

Figures 5 and 6 partially show the Web site for this sample application. Figure 5 shows the input screen and Figure 6 shows the output after the Optimize button is clicked.

\section{Schools Optimization DSS, A Web-Enabled Decision Support System}

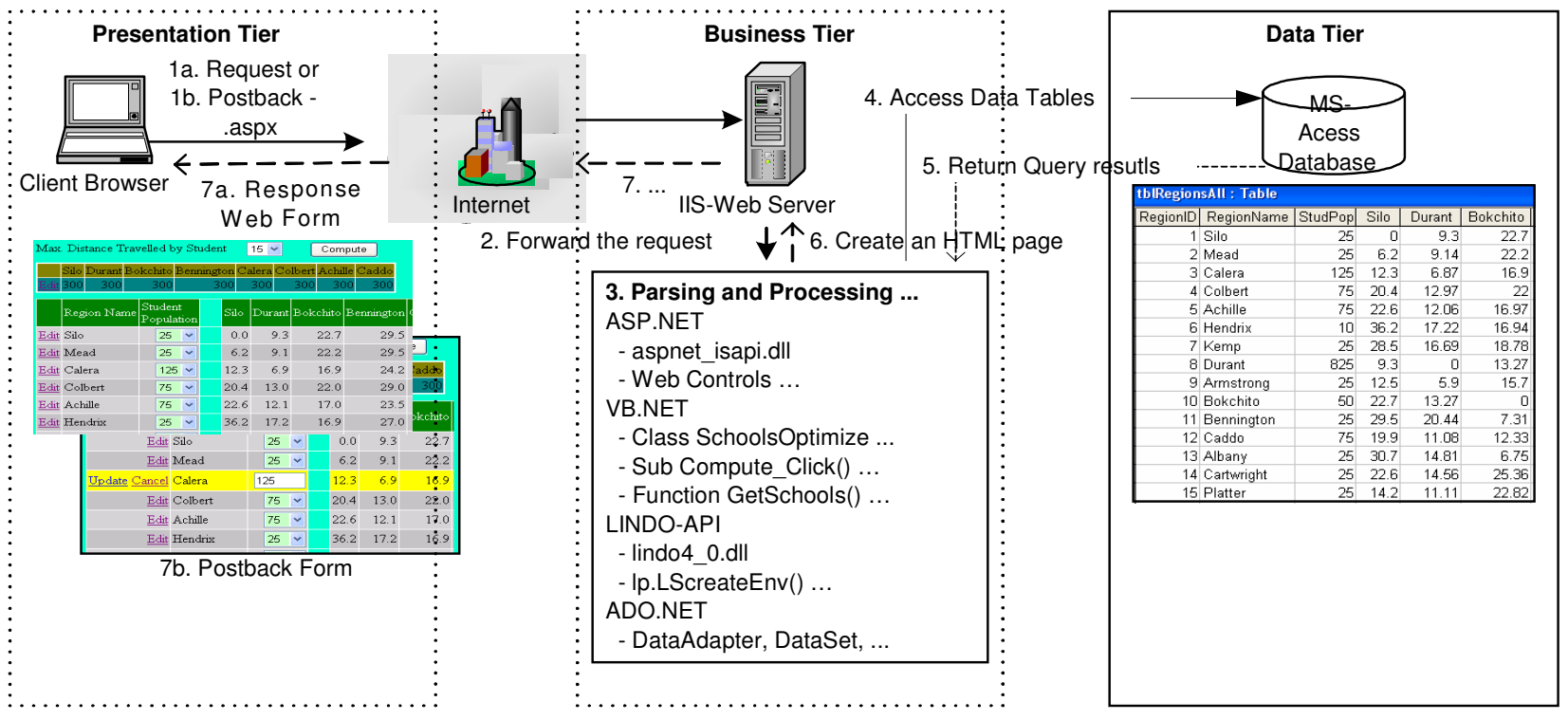

Figure 3. The DSS Structure 


\begin{tabular}{|c|c|c|c|c|c|c|}
\hline & $\begin{array}{l}\text { Region } \\
\text { Name }\end{array}$ & $\begin{array}{l}\text { Current } \\
\text { Student } \\
\text { Number }\end{array}$ & & $\begin{array}{l}\text { Region } \\
\text { Name }\end{array}$ & $\begin{array}{l}\text { Curre } \\
\text { Studes } \\
\text { Numb }\end{array}$ & \\
\hline$\underline{\text { Edit }}$ & Silo & $25 \backsim$ & $\underline{\text { Edit }}$ & Silo & 25 & $\sim$ \\
\hline Update Cancel & Mead & Number Required & Update Cancel & Mead & 5001 & Between $\theta-500 \theta$ \\
\hline
\end{tabular}

Figure 4. Required-Field and Range Validation web Controls

\section{WebForm1 - Microsoft Internet Explorer}

Eile Édit View Fạvorites Iools Help

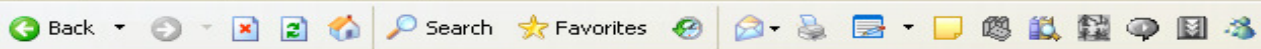

Address hittp://164.58.125.200/WebApps/Lindo1/Webform1.aspx $\quad \vee$ Links "

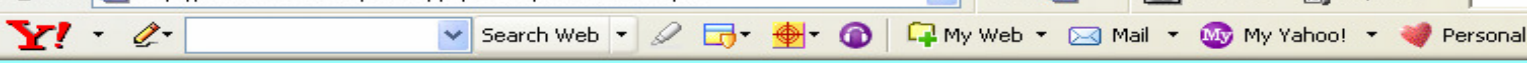

Maximum Distance Travel by Students: $15 \vee$ Optimize Reset

There are currently 8 schools in 19 regions.

Please click the Optimize button to see the new result.

\begin{tabular}{|c|c|c|c|c|c|c|c|c|}
\hline Schools & Silo & Durant & Bokchito & Bennington & Calera & Colbert & Achille & Caddo \\
\hline Curre & $300 \vee$ & $300 \vee$ & $300 \vee$ & $300 \vee$ & $300 \vee$ & $300 \vee$ & $300<$ & 300 \\
\hline
\end{tabular}

\begin{tabular}{|c|c|c|c|c|c|c|c|c|c|c|c|c|}
\hline & $\begin{array}{l}\text { Region } \\
\text { Name }\end{array}$ & $\begin{array}{l}\text { Curren } \\
\text { Student } \\
\text { Number }\end{array}$ & & Schools $=>$ & Silo & Durant & Bokchito & Bennington & Calera & Colbert & Achille & Caddo \\
\hline$\underline{E \text { dit }}$ & Silo & 25 & $\checkmark$ & Distance from to & 0.0 & 9.3 & 22.7 & 29.5 & 12.3 & 20.4 & 22.6 & 19.9 \\
\hline$\underline{E \text { dit }}$ & Mead & 25 & $\checkmark$ & Distance from to & 6.2 & 9.1 & 22.2 & 29.5 & 7.7 & 10.1 & 14.0 & 18.7 \\
\hline Edit & Calera & 125 & $\checkmark$ & Distance from to & 12.3 & 6.9 & 16.9 & 24.2 & 0.0 & 6.2 & 6.6 & 17.9 \\
\hline$\underline{\underline{E} \text { dit }}$ & Colbert & 75 & $\checkmark$ & Distance from to & 20.4 & 13.0 & 22.0 & 29.0 & 6.2 & 0.0 & 6.5 & 24.0 \\
\hline Edit & Achille & 75 & $\checkmark$ & Distance from to & 22.6 & 12.1 & 17.0 & 23.5 & 6.6 & 6.5 & 0.0 & 22.0 \\
\hline
\end{tabular}

Figure 5. Website Input

\section{EebForm1 - Microsoft Internet Explorer}

Eile Édit View Favorites Iools Help

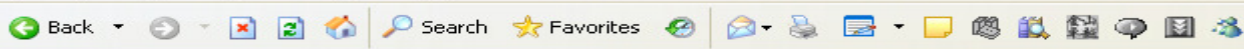

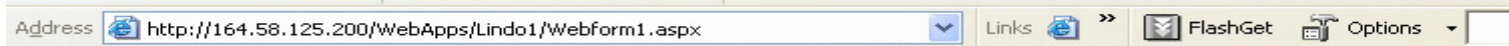

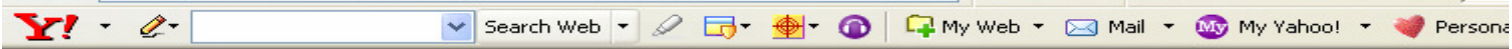

Maximum Distance Travel by Students: $15 \vee$ Optimize Reset

After optimization, we can have 6 schools (in orange color) in 19 regions,

provided no student traveling more than 15 miles out of their regions.

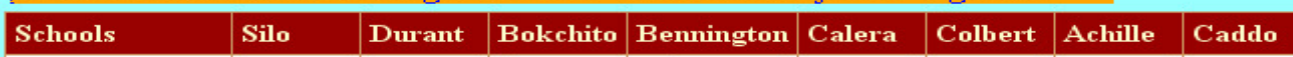

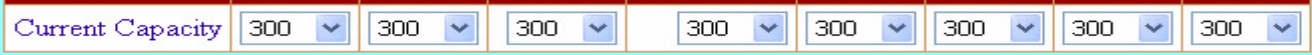

\begin{tabular}{|c|c|c|c|c|c|c|c|c|c|c|c|c|}
\hline & $\begin{array}{l}\text { Region } \\
\text { Name }\end{array}$ & $\begin{array}{l}\text { Curx } \\
\text { Stude } \\
\text { Numb }\end{array}$ & & Schools $=>$ & Silo & Durant & Bolkchito & Bennington & Calera & Colbert & Achille & Caddo \\
\hline$\underline{E \text { dit }}$ & Silo & 25 & $\checkmark$ & Students from to & 25 & & & & & & & \\
\hline$\underline{\text { Edit }}$ & Mead & 25 & $\checkmark$ & Students from to & 25 & & & & & & & \\
\hline$\underline{E \text { dit }}$ & Calera & 125 & $\checkmark$ & Students from to & & & & & 125 & & & \\
\hline$\underline{\text { Edit }}$ & Colbert & 75 & $\checkmark$ & Students from to & & & & & & & 75 & \\
\hline$\underline{E \text { dit }}$ & Achille & 75 & 2 & Studerts from to & & & & & & & 75 & \\
\hline$\underline{\text { Edit }}$ & Hendrix & 25 & 2 & Students from to & & & & & & & 25 & \\
\hline$\underline{\text { Edit }}$ & Kemp & 25 & $\checkmark$ & Students from to & & & & & & & 25 & \\
\hline Edit & Durant & 825 & $\checkmark$ & Students from to & 250 & 300 & & & 150 & & & 125 \\
\hline$\underline{\text { Edit }}$ & Armstrong & 25 & $\checkmark$ & Students from to & & & & & & & & 25 \\
\hline
\end{tabular}

Figure 6. Website Output 


\section{CONCLUSION}

In line with this year's IACIS conference theme of the changing role of IS education and AACSB's recent mandates, a need exists for integrating management science training into IS curriculum. Specifically, the need exists for developing Webenabled DSS that incorporate math optimization, thus providing accessibility to solve large-scale problems by users that do not have a math or technical background. We demonstrated that LINDO API, VB.NET, ASP.NET and Microsoft Access database are the only software required. Student versions of LINDO API are available as \$25 downloads from LINDO Systems (www.lindo.com). Larger versions capable of solving realistic problems can be purchased for $\$ 195$ to $\$ 995$.

We propose that the IS curriculum be modified to require a management science/operations research course emphasizing linear programming modeling. In parallel, students can take a fundamental programming class which will teach the Graphical User Interface (GUI) design as well as other programming concepts, followed by a tailored WebProgramming class which teaches the basic knowledge of HTML, Database, and Web Controls such as DataGrid, DatList, and Repeater in ASP.NET. Textbooks written by Gaddis [2] and Ullman [10] are good starters. These courses would serve as the prerequisites to the IS courses that teach Web-enabled/Windows DSS using math modeling and optimization.

\section{REFERENCES}

1. Cohen, M., Kelly, C., \& Medaglia, A. (2001). Decision support with Web-enabled software. Interfaces, 31, 109.
2. Gaddis, T. Irvine, K. \& Denton B. (2003). Starting out with Visual Basic .NET, $2^{\text {nd }}$. El Granada, CA: Thomson Delmar Learning.

3. Grossman, T. (2003). Getting down to business. ORMS Today, 30(4), 18-21.

4. Heinrichs, L. R. \& McDonald, J. (2006). The state of IS enrollments: Have we turned the corner?, Proceedings of the 2006 SWDSI Conference, Oklahoma City.

5. Kontzer, T. (2003). Owens \& Minor takes supply chain deeper. Information Week, 956(Sept 22), 47.

6. Lee, Y. \& Chen, E. (2002). BASF uses a framework for developing Web-based production-planning-optimization tools. Interfaces, 32, 15.

7. Livernash, T. \& Heuer, J. (2003). Web-based load planning \& optimization: Getting more for your transportation dollars by exploiting Webbased technology. Flow Logistics. Retrieved December 11, 2005 from www.loadopt.com/Documents/InternetOptimizat ionWhitePaperV8.pdf .

8. Luo, Y., Chen, C., Yucesan, E., \& Lee, I. (2000). Distributed Web-based simulation optimization, Proceedings of the 2000 Winter Simulation Conference, Retrieved December 12, 2005 from www.informs-cs.org/wsc00papers/245.PDF .

9. Ragsdale, C. T. (2004). Spreadsheet Modeling and Decision Analysis. Mason, OH:Thomson South-Western.

10. Ullman, C. Kauffman, J. Hart, C. \& Sussman D. (2004). Beginning ASP.NET 1.1 with VB.NET 2003. Indianapolis, IN: Wiley.

11. Winston, W. L. \& Albright, S. C. (2000). Practical Management Science. Pacific Grove, CA: Duxbury. 